\title{
Abiotic nitrate incorporation, anaerobic microsites, and the ferrous wheel
}

\author{
Benjamin P. Colman • Noah Fierer • \\ Joshua P. Schimel
}

Received: 15 October 2008 / Accepted: 2 December 2008 / Published online: 20 December 2008

(C) The Author(s) 2008. This article is published with open access at Springerlink.com

\begin{abstract}
Nitrate has long been thought to be chemically unreactive in soil. This view was challenged by the report of an apparently abiotic process whereby nitrate $\left(\mathrm{NO}_{3}{ }^{-}\right)$is incorporated into organic compounds (Dail et al. 2001). In Colman et al. (2007), we examined how common this process might be by testing for it in 45 soils collected from across a range of ecosystem types. We found no evidence of this process occurring in any of the soils, but found evidence of an analytical artifact that creates the appearance of incorporation. We suggested that prior evidence of this process might be due in part or in total to this analytical artifact. Davidson et al. (2008), however, challenged our results and conclusions, suggesting that we failed to observe the abiotic incorporation because we eliminated the anaerobic microsites they argue are necessary for the process. We address the criticisms, and show that they actually raise questions about the
\end{abstract}

B. P. Colman $(\varangle) \cdot$ J. P. Schimel

Department of Ecology, Evolution and Marine Biology, University of California, Santa Barbara,

CA 93106-9610, USA

e-mail: colmanb@gmail.com

\section{N. Fierer}

Department of Ecology and Evolutionary Biology,

University of Colorado, Boulder, CO 80309, USA

N. Fierer

Cooperative Institute for Research in Environmental

Sciences, University of Colorado, Boulder,

CO 80309, USA robustness of the only study to have reported abiotic $\mathrm{NO}_{3}{ }^{-}$incorporation in sterile soils. We argue that this area of research needs new artifact-free experiments if the controversy is going to be resolved.

Keywords Abiotic nitrate incorporation - Iron · Nitrogen deposition $\cdot$ Nitrogen retention

\section{Introduction}

Through burning fossil fuels and intensifying agriculture and industry, humans have increased the amount of reactive nitrogen released into the environment by $\sim 200 \%$ since preindustrial times (Galloway et al. 2008). Much of that $\mathrm{N}$ falls on $\mathrm{N}$-limited forest ecosystems as nitrate $\left(\mathrm{NO}_{3}{ }^{-}\right)$. A surprising amount of that $\mathrm{NO}_{3}{ }^{-}$is retained in soil organic matter (SOM, Galloway et al. 2008; Aber et al. 1998). If it were taken up by plants and returned later to the soil as litter, there should be a measurable plant growth response, while if it were taken up directly by soil microorganisms, there should be some combination of increased microbial biomass, accelerated litter decay, or increased $\mathrm{CO}_{2}, \mathrm{NO}$ and/or $\mathrm{N}_{2} \mathrm{O}$ production. These phenomena have not been observed in temperate forests in the US and Europe that experience elevated $\mathrm{NO}_{3}{ }^{-}$deposition (Aber et al. 1998). Additionally, laboratory studies of ${ }^{15} \mathrm{NO}_{3}{ }^{-}$turnover showed a short initial phase of rapid $\mathrm{NO}_{3}{ }^{-}$disappearance before the longer period of steady slow uptake 
(Berntson and Aber 2000; Davidson et al. 1991). The inability to explain these results by biological mechanisms led researchers to hypothesize that they were the result of abiotic chemical reactions incorporating $\mathrm{NO}_{3}{ }^{-}$into organic matter.

Without evidence of $\mathrm{NO}_{3}^{-}$assimilation into organic forms by abiotic reactions in sterile soils, this hypothesis remained intriguing but highly speculative. Thus, several researchers have tried to test the abiotic uptake hypothesis directly. The first such study was by Dail et al. (2001) who reported ${ }^{15} \mathrm{NO}_{3}{ }^{-}$ incorporation into a dissolved organic form, using soil from the Harvard Forest Long Term Ecological Research (LTER) site. To explain the results of that experiment, Davidson et al. (2003) proposed a mechanism that they called the "ferrous wheel hypothesis." In the ferrous wheel, $\mathrm{Fe}^{3+}$ is reduced by organic matter to $\mathrm{Fe}^{2+}$, which in turn reduces $\mathrm{NO}_{3}{ }^{-}$to $\mathrm{NO}_{2}{ }^{-}$; $\mathrm{NO}_{2}{ }^{-}$then reacts with phenolic molecules to form dissolved organic nitrogen compounds.

The second test for abiotic incorporation on sterile soils looked at $\mathrm{NO}_{3}{ }^{-}, \mathrm{NO}_{2}{ }^{-}$, and $\mathrm{NH}_{4}{ }^{+}$in three forest soils from plots dominated by different hardwood tree species in the Catskill Mountains, NY (Fitzhugh et al. 2003). They found little evidence of abiotic $\mathrm{NO}_{3}{ }^{-}$and $\mathrm{NH}_{4}{ }^{+}$incorporation, but did observe $\mathrm{NO}_{2}^{-}$incorporation.

Given these conflicting results, our recent study (Colman et al. 2007) was designed to evaluate how broadly this process occurs in soil. We tested for abiotic $\mathrm{NO}_{3}{ }^{-}$incorporation in 45 soils, including soils from the Harvard Forest and the Catskills, as well as soils from across North and South America. We found no evidence of abiotic incorporation in any of the soils we tested. Rather, we found that soluble iron, by interfering in a common colorimetric $\mathrm{NO}_{3}{ }^{-}$analysis, could create the appearance of abiotic incorporation of $\mathrm{NO}_{3}{ }^{-}$into a dissolved organic pool. We found the artifact in many soils, including an organic soil from the Harvard Forest, the same soil studied in Dail et al. (2001), which suggested that at least some of their reported incorporation might have been due to an analytical artifact.

\section{Criticisms addressed}

In a recent paper, Davidson et al. (2008) challenged the conclusions of Colman et al. (2007). While they reinforced our findings that the iron artifact can occur, they argued that it should not have been a problem in the analyses of Dail et al. (2001) because Fe concentrations were likely not high enough to cause measureable interference. They also challenged our results, arguing that our methods prevented us from observing this process. Much of what Davidson et al. (2008) reported is solid and reliable. They did standard additions of $\mathrm{NO}_{3}^{-}$to extracts of autoclaved Harvard Forest soils with low soluble iron concentrations, and found no evidence of an iron artifact. They also suggest this as a way to test for iron interference; standard additions are indeed the 'Gold Standard' of analytical chemistry, and at the low Fe concentrations found in most soil solutions the standard colorimetric analysis is not problematic.

However, we take issue with the arguments raised by Davidson et al. (2008) as to why we did not see abiotic incorporation in the soils we tested while they apparently did, as well as with the conclusions they draw from this apparent discrepancy. The criticisms focused on two aspects of our work: our kinetic analysis of our data, and our sterilization pre-treatment. Their description of our kinetic analysis is incorrect. In contrast, their criticism of our sterilization pretreatment-autoclaving small samples three times destroys anaerobic microsites-is likely accurate, but raises questions as to whether Dail et al. (2001) could have observed abiotic $\mathrm{NO}_{3}{ }^{-}$incorporation in their experiment.

Davidson et al. (2008) criticized our kinetic analysis, arguing that we assumed $\mathrm{NO}_{3}{ }^{-}$reduction would be first-order on $\mathrm{NO}_{3}{ }^{-}$concentration; that is incorrect. The isotherm approach we used is a standard analytical method and involves no assumptions as to the chemical order of reaction. Instead, it can potentially reveal the chemical order and give insight into mechanism. Simple first-order effects would reduce the slope of the line of measured vs. added $\mathrm{NO}_{3}{ }^{-}$below one, but other chemical effects would either make it non-linear and/or create a non-zero intercept. We analysed changes in the slope only because we did not observe any such other effects, as stated in Colman et al. (2007). Here we show (Fig. 1), our results for the Harvard Forest organic soil included in Colman et al. (2007) to clarify those results. Had we found a fixed amount of abiotic incorporation equivalent to that reported by Dail et al. (2001), we would have observed the response shown by the dashed line, with 


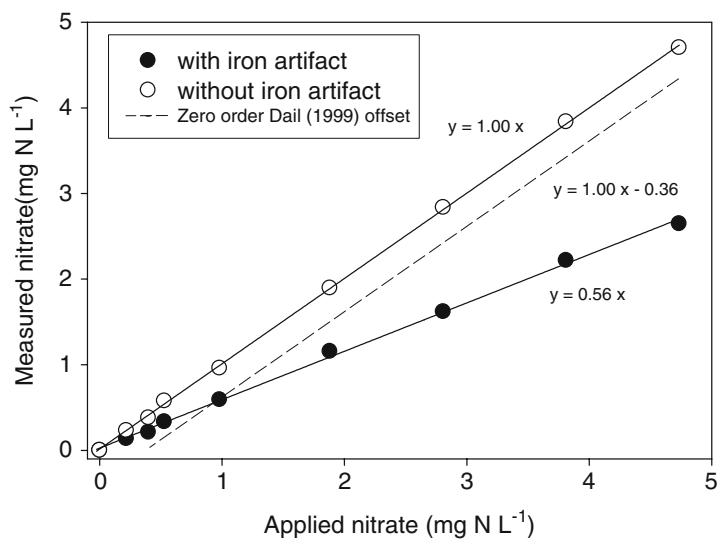

Fig. 1 Adsorption isotherm of $\mathrm{NO}_{3}{ }^{-}$in Harvard Forest organic soil. Closed circles $(\mathbf{O})$ represent samples measured with iron artifact; open circles $(\bigcirc)$ represent samples measured without iron artifact. Measured $\mathrm{NO}_{3}{ }^{-}$concentrations are corrected for background $\mathrm{NO}_{3}{ }^{-}$which was measured as 0.8 and 1.1 for samples as measured with iron artifact and without iron artifact, respectively

an easily measurable negative intercept. Rather, what we found after removing the $\mathrm{Fe}$ artifact was a response equivalent to the 1:1 line. With the iron artifact included there was a straight line with a reduced slope, giving the false appearance of abiotic incorporation. If these results represented something other than an artifact, they would indeed suggest a process that appears to be first-order with respect to $\mathrm{NO}_{3}{ }^{-}$.

The second criticism of our work that Davidson et al. (2008) makes is that we failed to observe abiotic incorporation because we autoclaved soils three times over several days, and thus destroyed the anaerobic microsites that they argue are essential for abiotic $\mathrm{NO}_{3}{ }^{-}$incorporation to occur. We agree, unequivocally, that our sample treatment likely destroyed anaerobic microsites. Autoclaving kills the microbes that consume oxygen and drive microsites to anaerobiosis in the first place. It also pumps hot, pressurized steam $\left(121^{\circ} \mathrm{C}\right.$ at $\sim 2$ atmospheres) into soil pores, which is then replaced with ambient air when the autoclave is vented. Furthermore, oxygen freely diffuses through the soil during the time between autoclaving cycles. Even autoclaving sealed vials of anaerobic sediment increases the redox state of that sediment (Tratnyek and Wolfe 1993). Thus regardless of sample size, it is unlikely that anaerobic microsites would survive one autoclave cycle, let alone multiple cycles as used by Dail et al. (2001) and Colman et al. (2007).

\section{Implications}

If Davidson et al. (2008) are correct, that we failed to observe $\mathrm{NO}_{3}{ }^{-}$incorporation because our autoclaving regime destroyed anaerobic microsites, then Dail et al. (2001) should not have observed this process either. In fact, if abiotic $\mathrm{NO}_{3}{ }^{-}$incorporation occurs and requires anaerobic microsites, it is unlikely that it would be observed in any sterilized soil, whether it is autoclaved or sterilized in some other fashion. Conversely, if abiotic $\mathrm{NO}_{3}{ }^{-}$incorporation does occur, and Dail et al. (2001) did observe it, it probably involves chemistry that can occur under currently aerobic conditions and does not rely on the immediate existence of anaerobic microsites; in this case we should also have observed it. We did not-we observed only the iron artifact. If anaerobic microsites are important to rapid $\mathrm{NO}_{3}{ }^{-}$incorporation, their likely destruction by sterilization raises questions about the results of Dail et al. (2001), questions that can only be addressed by robust experimentation.

\section{The ferrous wheel hypothesis}

The idea that anaerobic conditions are important to rapid abiotic incorporation of $\mathrm{NO}_{3}{ }^{-}$in soils arises from the ferrous wheel hypothesis. We have suggested that the conditions required for the ferrous wheel mechanism to work are unlikely to occur in sterilized soils, but perhaps it could still apply in live soils and thereby explain observations of rapid $\mathrm{NO}_{3}{ }^{-}$ immobilization. While the answer to this question is beyond the scope of this paper, there are problems with the proposed mechanism that suggest it may be unlikely to explain rapid incorporation of $\mathrm{NO}_{3}{ }^{-}$even in "live" soils.

These problems lie in the second step of the ferrous wheel hypothesis, the reaction of $\mathrm{Fe}^{2+}$ with $\mathrm{NO}_{3}{ }^{-}$. This reaction is thermodynamically favorable, but slow without a catalyst (Ottley et al. 1997). Davidson et al. (2003) suggested copper, green rust, and $\mathrm{Fe}^{2+}$ adsorbed on mineral surfaces as possible catalysts. There are two aspects to the catalysis of this reaction that suggest it would not occur as postulated. First, while all of these possible catalysts promote $\mathrm{NO}_{3}{ }^{-}$ reduction, none have $\mathrm{NO}_{2}^{-}$as their end product. Copper and green rusts yield $\mathrm{NH}_{3}$ (Ottley et al. 1997; Hansen et al. 1996), while adsorbed $\mathrm{Fe}^{2+}$ yields $\mathrm{N}_{2}$ 
(Postma 1990). Second, it appears improbable that this catalysis would happen in the acid forest soils where abiotic $\mathrm{NO}_{3}{ }^{-}$incorporation has been hypothesized to occur. The amount of copper needed to catalyze $\mathrm{NO}_{3}{ }^{-}$reduction is higher than is reasonable in soils (Ottley et al. 1997). While mixed valence iron minerals are not uncommon (Weber et al. 2001; Campbell and Torgersen 1980), they do not appear to catalyze $\mathrm{NO}_{3}{ }^{-}$reduction at relevant rates without biology (Senn and Hemond 2002; Matocha and Coyne 2007). As for green rust, while it does spontaneously reduce $\mathrm{NO}_{3}{ }^{-}$to $\mathrm{NH}_{3}$ in anaerobic soils, the reaction requires high $\mathrm{pH}$, which is unlikely in acid soils.

Thus, we believe there are problems with the ferrous wheel hypothesis: the slow kinetics of $\mathrm{Fe}^{2+}$ reduction of $\mathrm{NO}_{3}{ }^{-}$, evidence that proposed catalysts produce $\mathrm{NH}_{3}$ or $\mathrm{N}_{2}$ (rather than $\mathrm{NO}_{2}^{-}$), questions about the one study that did report abiotic $\mathrm{NO}_{3}{ }^{-}$ incorporation in sterile soils, and direct measurements that failed to find abiotic $\mathrm{NO}_{3}{ }^{-}$incorporation. These all suggest that the ferrous wheel mechanism is unlikely to explain either rapid immobilization of $\mathrm{NO}_{3}{ }^{-}$or the observation of high ecosystem $\mathrm{N}$ retention that originally stimulated its development.

\section{Conclusions}

Davidson et al. (2008) shows that the controversy over abiotic incorporation of $\mathrm{NO}_{3}{ }^{-}$into organic forms in soil remains unresolved. It reported retrospective chemical analyses on newly collected soils to suggest the original results by Dail et al. (2001) were robust. However, it also raised arguments that pose questions about those results and of the hypothesized ferrous wheel mechanism itself. In contrast, neither Fitzhugh et al. (2003) nor Colman et al. (2007) found significant evidence of abiotic $\mathrm{NO}_{3}{ }^{-}$incorporation in a wide range of soils, and Colman et al. (2007) demonstrated the occurrence of an artifact in many that produced the appearance of abiotic incorporation in sterilized soils. The Colman et al. (2007) and Dail et al. (2001) studies used related methods, but different samples; therefore they may not be directly comparable and may not be in contradiction with each other. However, this is impossible to evaluate without knowing the extent of Fe-interference in the samples and analyses of Dail et al. (2001). We agree that the discrepancy in Fe analyses mentioned by Davidson et al. (2008) would be disturbing if they were on the same samples as used in the earlier studies, but since they were not, it merely suggests substantial differences among the samples. We believe that disagreements between our work and that of Dail et al. (2001), disagreements that raise questions about the very occurrence of abiotic $\mathrm{NO}_{3}{ }^{-}$incorporation into $\mathrm{SOM}$, as well as about the hypothesized ferrous wheel hypothesis, cannot be resolved by post-hoc chemical testing and debate. Rather, they can only be resolved by new, independent experiments using analytical methods that are demonstrably artifact-free at the time the experiments are done.

Ultimately, though, we believe that we should return to original question of how $\mathrm{NO}_{3}{ }^{-}$is retained in forest soils without leaving a stronger biological signal, and consider a wider range of possible mechanisms. Is it driven by abiotic reactions of $\mathrm{NO}_{3}{ }^{-}$? Is it a result of biological reduction of $\mathrm{NO}_{3}{ }^{-}$to $\mathrm{NO}_{2}{ }^{-}$or $\mathrm{NH}_{3}$ (Senn and Hemond 2002; Matocha and Coyne 2007; Silver et al. 2001) followed by abiotic incorporation of that $\mathrm{NO}_{2}^{-}$or $\mathrm{NH}_{3}$ (Fitzhugh et al. 2003; Johnson et al. 2000; Barrett et al. 2002)? Or, is it entirely biological and we are just missing the signal?

Open Access This article is distributed under the terms of the Creative Commons Attribution Noncommercial License which permits any noncommercial use, distribution, and reproduction in any medium, provided the original author(s) and source are credited.

\section{References:}

Aber J, McDowell W, Nadelhoffer K, Magill A, Berntson G, Kamakea M, McNulty S, Currie W, Rustad L, Fernandez I (1998) Nitrogen saturation in temperate forest ecosystems: hypotheses revisited. Bioscience 48:921-934. doi:10.2307/ 1313296

Barrett JE, Johnson DW, Burke IC (2002) Abiotic nitrogen uptake in semiarid grassland soils of the U.S. Great Plains. Soil Sci Soc Am J 66:979-987

Berntson GM, Aber JD (2000) Fast nitrate immobilization in N saturated temperate forest soils. Soil Biol Biochem 32:151157. doi:10.1016/S0038-0717(99)00132-7

Campbell P, Torgersen T (1980) Maintenance of iron meromixis by iron redeposition in a rapidly flushed monimolimnion. Can J Fish Aquat Sci 37:1303-1313. doi:10.1139/f80-166

Colman BP, Fierer N, Schimel JP (2007) Abiotic nitrate incorporation in soil: is it real? Biogeochemistry 84:161-169. doi:10.1007/s10533-007-9111-5

Dail DB, Davidson EA, Chorover J (2001) Rapid abiotic transformation of nitrate in an acid forest soil. Biogeochemistry 54:131-146. doi:10.1023/A:1010627431722 
Davidson EA, Hart SC, Shanks CA, Firestone MK (1991) Measuring gross nitrogen mineralization, immobilization, and nitrification by ${ }^{15} \mathrm{~N}$ isotopic pool dilution in intact soil cores. J Soil Sci 42:335-349. doi:10.1111/j.1365-2389. 1991.tb00413.x

Davidson EA, Chorover J, Dail DB (2003) A mechanism of abiotic immobilization of nitrate in forest ecosystems: the ferrous wheel hypothesis. Glob Change Biol 9:228-236. doi:10.1046/j.1365-2486.2003.00592.x

Davidson EA, Chorover J, Dail DB (2008) Iron interference in the quantification of nitrate in soil extracts and its effect on hypothesized abiotic immobilization of nitrate. Biogeochemistry 90:65-73. doi:10.1007/s10533-008-9231-6

Fitzhugh RD, Lovett GM, Venterea RT (2003) Biotic and abiotic immobilization of ammonium, nitrite, and nitrate in soils developed under different tree species in the Catskill Mountains, New York, USA. Glob Change Biol 9:15911601. doi:10.1046/j.1365-2486.2003.00694.x

Galloway JN, Townsend AR et al (2008) Transformation of the nitrogen cycle: recent trends, questions, and potential solutions. Science 320(5878):889-892

Hansen HCB, Koch CB, Nancke-Krogh H, Borggaard OK, Sørensen J (1996) Abiotic nitrate reduction to ammonium: key role of green rust. Environ Sci Technol 30:2053-2056. doi:10.1021/es950844w
Johnson DW, Cheng W, Burke IC (2000) Biotic and abiotic nitrogen retention in a variety of forest soils. Soil Sci Soc Am J 64:1503-1514

Matocha CJ, Coyne MS (2007) Short-term response of soil iron to nitrate addition. Soil Sci Soc Am J 71:108-117

Ottley CJ, Davison W, Edmunds WM (1997) Chemical catalysis of nitrate reduction by iron(II). Geochim Cosmochim Acta 61:1819-1828. doi:10.1016/S0016-7037(97)00058-6

Postma D (1990) Kinetics of nitrate reduction by detrital Fe(II)-silicates. Geochim Cosmochim Acta 54:903-908. doi:10.1016/ 0016-7037(90)90384-W

Senn DB, Hemond HF (2002) Nitrate controls on iron and arsenic in an urban lake. Science 296:2373-2376. doi:10.1126/science. 1072402

Silver WL, Herman DJ, Firestone MK (2001) Dissimilatory nitrate reduction to ammonium in upland tropical forest soils. Ecology 82:2410-2416

Tratnyek PG, Wolfe NL (1993) Oxidation and acidification of anaerobic sediment-water systems by autoclaving. J Environ Qual 22:375-378

Weber KA, Picardal FW, Roden EE (2001) Microbially catalyzed nitrate-dependent oxidation of biogenic solid-phase $\mathrm{Fe}(\mathrm{II})$ compounds. Environ Sci Technol 35:1644-1650. doi:10.1021/es0016598 